\title{
TERNARY FUEL MIXTURE OF DIESEL, RAPESEED OIL AND TYRE PYROLYTIC OIL SUITABLE FOR MODERN CRDI ENGINES
}

\author{
Marta AMBROSEWICZ-WALACIK ${ }^{1^{*}}$, Sławomir WIERZBICKI ${ }^{2}$, \\ Maciej MIKULSKI ${ }^{3}$, Tomasz PODCIBORSKI ${ }^{4}$ \\ 1,2Dept of Mechatronics and IT Education, Faculty of Technical Sciences, \\ University of Warmia and Mazury in Olsztyn, Poland \\ ${ }^{3}$ TNO Automotive, Department Powertrains, Helmond, The Netherlands \\ ${ }^{4}$ Dept of Planning and Spatial Engineering; Faculty of Geodesy, Geospatial and Civil Engineering; \\ University of Warmia and Mazury in Olsztyn, Poland
}

Received 28 November 2016; revised 22 May 2017; accepted 2 September 2017

\begin{abstract}
The focus on seeking alternative fuels for combustion engines has been on the environmental and political scene for many years. Simultaneously there is a more and more serious problem of non-degradable waste utilization. In the present work an attempt has been made to asses both of those aspects by proposing a tailor-made, 3-component mixture consisting of mineral diesel, crude rapeseed oil and waste tyre pyrolytic oil. It was proven that the addition of pyrolytic oil can improve some basic drawbacks of rapeseed oil / diesel mixtures like high density and viscosity or low cold filter plugging point. On the basis of maximum bio-component share and optimum physicochemical properties a best fuel sample (40\% mineral diesel oil, 55\% rapeseed oil and 5\% pyrolytic oil fraction) had been selected for engine tests, performed on a lightduty multi-cylinder Compression Ignition (CI) engine with electronic, Common Rail (CR) injection system. The steady state tests were performed for two rotational speeds and two injection strategies (single and sequential fuel injection), for each of which a full load sweep was performed. The engine research included in-cylinder pressure analysis along with efficiency estimation and exhaust gas emission measurements. The research confirmed the assumption that the selected fuel mixture is suitable for modern CI engines. The specific fuel consumption was similar or lower for the tested fuel compared to standard diesel, except the cases were sequential injection was incorporated. Emissions remained on similar levels as for both fuels except Total HydroCarbons (THC) at sequential injection operation points, which correlated with lower fuel conversion efficiency.
\end{abstract}

Keywords: compression ignition, common rail, diesel, crude rapeseed oil, pyrolytic oil, waste tyres, combustion analysis, exhaust emissions.

\section{Notations}

Variables and functions:

$H R R$ - heat release rate $[\mathrm{J} / \mathrm{CA}]$;

$N$ - engine rotational speed [rpm];

$P$ - in cylinder pressure [bar];

$P_{e}$ - engine power $[\mathrm{kW}]$;

$T_{e}$ - engine torque $[\mathrm{N} \cdot \mathrm{m}]$;

$V_{d}$ - displacement volume $\left[\mathrm{cm}^{3}\right]$;

$\alpha$ - crankshaft rotation angle [CA];

$\eta_{v}$ - volumetric efficiency [\%];

$\rho_{\text {air }}$ - air density $\left[\mathrm{kg} / \mathrm{m}^{3}\right]$;

$V$ - cylinder volume $\left[\mathrm{cm}^{3}\right]$;

$$
\begin{aligned}
& \Delta p_{\text {avg }}(C A) \text { - } \text { average error of pressure measurement } \\
& \text { for each crank angle; } \\
& \Delta p_{\text {avg_r }}(C A) \text { - } \text { average relative error of cycle-averaged } \\
& \text { cylinder pressure }[\%] ; \\
& p_{\text {avg }}(C A) \text { - cycle-averaged cylinder pressure }[\mathrm{bar}] ; \\
& G_{\text {air }} \text { - air aspired to the engine }[\mathrm{kg} / \mathrm{h}] ; \\
& T_{\text {air }} \text { - intake air temperature }[\mathrm{K}] ; \\
& \alpha_{i d}-\text { ignition delay angle }\left[{ }^{\circ}\right] ; \\
& \mathrm{G}_{f u e l}-\text { fuel consumption }[\mathrm{kg} / \mathrm{h}] ;
\end{aligned}
$$

Abbreviations:

BSFCE - brake specific fuel conversion efficiency;

BSFC - brake specific fuel consumption;

${ }^{*}$ Corresponding author. E-mail: marta.ambrosewicz@uwm.edu.pl 


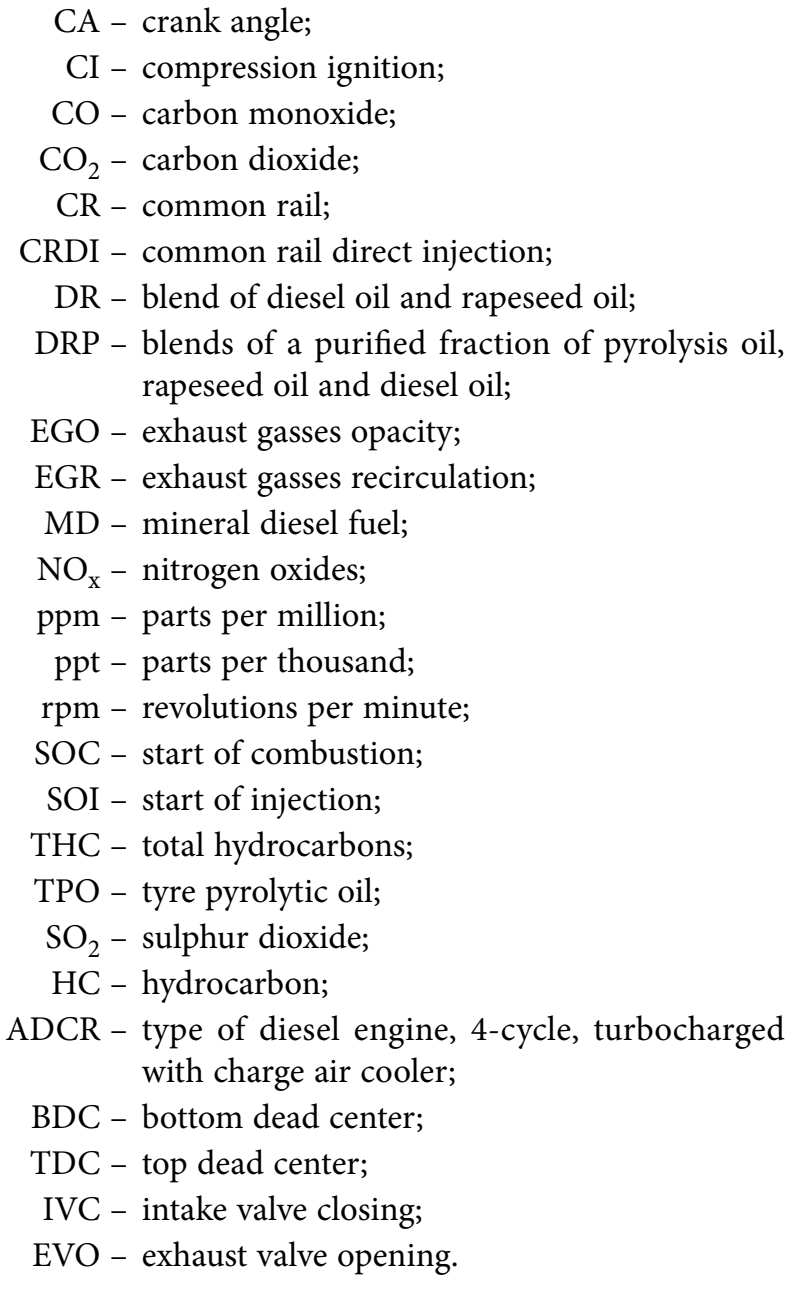

\section{Introduction}

Due to the fact that fossil fuels are being depleted, there is a need to find alternative sources for production of fuel to meet the energy demands of the world. Biodiesel is one of the best available resources that have come to the forefront recently (Atabani et al. 2012). Any source containing substantial amounts of fatty acids may be used as raw material for biodiesel production (Refaat 2010). Currently, plant raw materials are mainly used to produce liquid biofuels. Studies concerning production of biodiesel using materials of animal origin on a bench and pilot scale are also being conducted. It is also worth adding that due to economic and ecological reasons, it seems reasonable to use residual fats and oils, while domestic, commercial and industrial processing oil and fats can also be used as a material for production of this biofuel. The application of these raw materials is, however, associated with prior processes of oil purification, which are sometimes complex and expensive (Karmakar et al. 2010). It is generally believed that the choice of a suitable raw material depends on its availability, the chemistry and the economy of the process, as well as on the fat content (Karmakar et al. 2010; Sharma, Singh 2009). Namely, waste vegetable and animal fats are characterised by an increased content of compounds, which make difficult the transesterification (Tańska et al. 2012).

From an ecological point of view, the utilization of other waste, non-biodegradable materials like plastic solid waste or waste car tyres also seems an important issue (Luo et al. 2000). Choosing suitable methods for disposal of waste is one of the most important aspect from the energetic, environmental, economic and political point of view (Delattre et al. 2001). Panda et al. (2010) presented different technologies for plastic waste management, and some of them can be used for the utilization of rubber waste. The cited authors presented, among others, pyrolysis, which is defined as controlled burning or heating $\left(400 \ldots 700^{\circ} \mathrm{C}\right)$ of a material in the absence of oxygen. Organic components of pyrolysed material are decomposed, generating liquid and gaseous products that can be used as fuels, while inorganic ingredients remain practically unaltered and free of binding organic matter (Panda et al. 2010; Adrados et al. 2012). Venderbosch, Prins (2010) and Butler et al. (2011) reported that the above-mentioned process is classified into four categories: slow, fast, flash, and gasification, with the fast and flash types of pyrolysis being used to maximise the production of biodiesel - the main source of the liquid fuel. A similar composition of pyrolysis oil and petroleum indicates the possibility of application of these materials in the production of alternative fuels; therefore, technologies for processing waste tyres are constantly being improved. Surovka et al. (2012), based on the comparison of the calorific value of motor fuel (petrol $43 \ldots 45 \mathrm{MJ} / \mathrm{kg}$ and diesel fuel $42 \ldots 46 \mathrm{MJ} / \mathrm{kg}$ ) and waste motor oil $(44 \ldots 46 \mathrm{MJ} / \mathrm{kg})$ with calorific value of TPO $(43.5 \mathrm{MJ} / \mathrm{kg})$, demonstrated that these products are characterised by a similar value of this parameter. Considering the current tendency to search for renewable energy sources, the use of TPO to create fuel blends to power diesel engines is believed to be an opportunity. Regarding the possibility of using TPO in combustion engines, the literature survey showed different and sometimes conflicting results, which was explained by different properties of analysed fuels and different engine test methods. Koc and Abdullah (2014), analysing the possibility of using a tyre oil-biodiesel-diesel blend as fuel in a 4-cylinder diesel engine, found that blending 10\% TPO with biodiesel and diesel oil generated the highest torque and power outputs. What is more, $\mathrm{NO}_{\mathrm{x}}$ emissions for mixtures containing $10 \%$ biodiesel, $10 \%$ TPO and $80 \%$ diesel fuel were lower than for a fuel sample containing $10 \%$ biodiesel and $90 \%$ diesel fuel. Kegl (2011) indicated that high $\mathrm{NO}_{\mathrm{x}}$ emissions for biodiesel/diesel fuel blends were caused by a high combustion temperature, advanced injection and high oxygen content in the biofuel. On the other hand, low emissions of $\mathrm{NO}_{\mathrm{x}}$ from tyre oil blends were caused by a low level of nitrogen and aromatic compounds in these fuels (Murugan et al. 2008b). İlkılıç and Aydın (2011), based on engine performance and exhaust emissions of diesel oil blends with $5,10,15,25,35,50$ and $75 \%$ addition of TPO using 
a Rainbow-186 diesel engine, found that the lowest engine performance was observed for pure TPO in comparison to its blends with 25 and $50 \%$ of diesel fuel. The authors explained the reduction of power output for fuels based on TPO by their lower calorific value. The lowest torque and engine power were observed for pure TPO with an $11.86 \%$ average torque reduction and a $16.5 \%$ average power reduction in comparison to diesel fuel. What is more, TPO was characterised by a $12 \%$ higher BSFC than mineral fuel. Analysis of exhaust emissions indicated that samples prepared with the highest addition of TPO (50, 75 and $100 \%$ ) should not be intended for direct use in diesel engines due to a high level of $\mathrm{CO}, \mathrm{HC}, \mathrm{SO}_{2}$ and smoke emissions, while blends with lower amounts of TPO could be used directly in diesel engines. One the other hand, Doğan et al. (2012) reported that blends containing up to $70 \%$ of TPO can be used in diesel engines and improve some engine emission factors, especially smoke opacity, $\mathrm{CO}$ and $\mathrm{HC}$ emissions. The authors found that the amount of TPO addition to fuel blends $(10,30,50,70$ and $90 \%)$ did not have a significant impact on the engine output torque, engine power, brake specific energy consumption and brake thermal efficiency. However, with increasing addition of TPO in fuel mixtures, the $\mathrm{NO}_{\mathrm{x}}$ emissions marginally increase, while $\mathrm{HC}$ emissions and smoke opacity decrease. In study of Murugan et al. (2008b), fuel samples containing 10, 30 and $50 \%$ of TPO blended with diesel fuel were analysed in order to evaluate the performance, emission and combustion characteristics of a single cylinder direct injection diesel engine. Murugan et al. (2008a) observed that the brake thermal efficiency of the engine was higher for samples with lower addition of diesel fuel. Generally, the authors claimed that it is possible to use TPO as an alternative fuel, but the reduction of the content of aromatic compounds and viscosity is required. The main problem with using crude pyrolysis tyre oil is the fact that it contains char, sand and alkali metals, which could cause problems in the injection equipment and in other engine parts (Zabaniotou, Stavropoulos 2003). Moreover, tar and polymers derived from gummy materials contained in TPO, could generate the formation of deposits in the injection system. The authors claimed that carbonaceous deposits may be formed in the combustion chamber, exhaust valves and in the piston ring grooves while using this kind of fuel. Murugan et al. (2008a) trying to improve the properties of crude TPO, proposed a modification of the fuel by the removal of moisture, desulphurization and vacuum distillation. Authors found that the distillation process improved the heating value and reduced the viscosity and sulphur content of the TPO. Furthermore, based on the analysis of blends of crude and distilled TPO with diesel fuel (in proportion of 30:70) (TPO 30), observed that the mixture of the modified sample with diesel fuel (DTPO 30) was characterised by $8 \%$ lower $\mathrm{NO}_{\mathrm{x}}$ emissions than the mixture with a crude tyre sample.

In the present study, the results of an engine test carried out with the use of a blend consisting of diesel fuel, distilled fraction of tyre pyrolysis oil and crude rapeseed oil were presented. Despite the fact that a direct application of crude rapeseed oil causes operational and durability problems (Agarwal et al. 2008) authors decided to use it as one of blends components taking into account the possibility of improving properties of blends by the addition of fraction of pyrolytic oil. Moreover, it should be remembered that in areas where grid power is not available and it is not possible to conduct chemical processes, blending of vegetable oils may play a main role in decentralized power generation for irrigation and electrification. Moreover, the conducted pilot studies demonstrated that the addition of purified pyrolysis oil to crude rapeseed oil caused an increase in its viscosity and density and improved oxidative stability and volatility of the obtained mixtures - that is, parameters, which disqualify crude vegetable oils as fuels.

The above brief review of the recent studies concerning alternative liquid fuels shows that only a limited number of studies were previously performed to investigate the effect of tyre-derived pyrolysis fuel/diesel blends on engine performance and emissions. For example, Zhang and $\mathrm{Wu}$ (2014), examining the possibility of use the ternary blends of pyrolytic oil obtained from pyrolysed pine wood/glycerol/methanol, and taking into account the safety during fuels storage and transportation and the possible ratio of glycerol to methanol that may be obtained from biodiesel production process, found that potential feasible compositions of the mentioned compounds were: pyrolytic oil $\geq 70 \mathrm{wt} \%$; glycerol $\leq 20 \mathrm{wt} \%$; methanol $\leq 10 \mathrm{wt} \%$ ). The blends with recommended shares of individual fuel additives could be used as burner fuel for combustion applications. Cited authors noticed that prepared blends, compared to pyrolytic oil and glycerol as individual fuel, were characterized by improved discriminates in terms of density, viscosity and heating value. One the other hand, Koc et al. (2010), analysing exhaust emissions and engine performance of an engine fuelled with binary and ternary fuel blends consisted, respectively of $97 \%$ diesel and 3\% biodiesel or 3\% tyre oil, and $94 \%$ diesel, $3 \%$ tyre oil and $3 \%$ biodiesel. Cited authors found that ternary blend produced lower $\mathrm{NO}_{\mathrm{x}}$ emissions than binary blends of biodiesel and diesel and reduced the $\mathrm{CO}$ emissions compared to tyre oil diesel fuel blend. Moreover, Koc et al. (2010) stated that an addition of tyre oil to biodiesel or diesel fuels could be a suitable method of reducing $\mathrm{NO}_{\mathrm{x}}$ emissions from biodiesel containing fuel blend. Bridgwater and Canales (2013) presented the WO 2013027050 A1 patent that provides using the ternary blend consisting of a liquid condensate product of mixed wood fast pyrolysis (5...50 wt \%), biodiesel (5...50 wt\%) and alcohol (30...90 wt\%). Authors observed that pyrolytic wood oil dissolves in biodiesel only in small quantities. However, alcohols, such as ethanol, propanol as a good solvent for mentioned fuels can affect the miscibility. Bridgwater and Canales (2013) found that density of ternary mixtures containing $50 \mathrm{wt} \%$ of ethanol started to increase in the bottom layers, when the share of pyrolytic oil was increased, 
while the maximum value of that parameter was reached for sample composed of $50 \mathrm{wt} \%$ of ethanol, $30 \mathrm{wt} \%$ pyrolytic oil and $20 \mathrm{wt} \%$ of biodiesel. In turn, Raslavičius and Bazaras (2009), analysing the effect of addition of 5 and $10 \%$ of ethanol to blend consisting of $70 \%$ of diesel oil and $30 \%$ of rapeseed methyl ester, found that in case of $5 \%$ addition of alcohol the exploitation characteristics of the tractor unit were analogous within the total range of loads as operating on pure mineral diesel. Due to this fact authors suggested that sample with a lower addition of ethanol could be used in the areas especially sensitive to environmental pollution. In case of $10 \%$ addition of alcohol to fuel blend, Raslavičius and Bazaras (2009) noticed undesirable, uneven engine operation and increased emission level in the exhaust gases.

Presented above, problem of the miscibility of pyrolytic oil with diesel fuel can be also solved by the emulsification process. Mulimani and Navindgi (2017), examining the performance and emissions characteristics of a diesel engine fuelled with emulsions of diesel and pyrolytic oil obtained from pyrolysed de-oiled seed cake of mahula, found that brake thermal efficiency of the engine operated with mahula oil emulsions, compared to diesel oil, was found to be higher. In turn, the exhaust gas temperature was higher with an increase of pyrolytic oil share in prepared emulsions. The authors explained that by the more oxygen availability in the pyrolysis oil and increased combustion duration. What is more, there was observed that, compared with diesel oil, the smoke and $\mathrm{NO}_{\mathrm{x}}$ emissions were reduced in the case of emulsions with pyrolytic oil addition.

The results of tests performed on modern, high pressure CR injection engines are clearly lacking in this respect. In addition, none of the discussed research focused on the influence of three-component mixture on engine performance and emissions. However, a comparison of the results of available studies suggests that the addition of a purified fraction of pyrolysis oil to a mixture of DRP will have a positive impact on its physicochemical parameters, so it will be characterized by the properties closer to pure diesel fuel. Confirmation of this research assumption is the main purpose of the present paper. In order to validate it, samples of three-component mixtures were subjected to thorough physicochemical tests. Based on the results of the physicochemical tests, the most promising (in terms of maximizing the content of bio-components and physicochemical properties most similar to diesel) fuel sample was selected for engine tests. The tests were conducted on a light-duty, turbocharged, CRDI CI engine using factory engine controller with engine maps optimized for standard diesel operation. This was done in order to check whether the similar physicochemical parameters would enable the use of the selected fuel without the necessity of introducing large-scale hardware or software modifications to the engine. Steady state measurements were performed on wide range of operating points. In-cylinder pressures were analysed for both fuels, followed by efficiency and emissions analyses.

\section{Experimental sections}

\subsection{Preparation of samples and quality assessment method}

The experimental material consisted of commercial pressed rapeseed oil, commercial diesel oil and an industry sample of pyrolysis oil, that was obtained by pyrolysis process conducted in a reactor at approx. $450 \ldots 500{ }^{\circ} \mathrm{C}$ for approx. $8 \mathrm{~h}$ with limited oxygen concentration. The supplied sample of TPO was characterized in terms of density at $40{ }^{\circ} \mathrm{C}$, viscosity at $20{ }^{\circ} \mathrm{C}$, acid value, sulphur content, flash point and oxidative stability. Subsequently, the sample was subjected to a distillation process in order to isolate naphtha free from soot particles present in the initial sample. A laboratory set equipped with a heater, a three-neck flask fitted with a mercury thermometer and a thermocouple, spherical condenser, and collection vessel was used for the distillation of TPO. The process was conducted in three temperature ranges:

$->160^{\circ} \mathrm{C}$ to produce approx. $4 \%$ of light naphtha fraction;

$-160 \ldots 204^{\circ} \mathrm{C}$ to isolate approx. $56 \%$ of medium naphtha fraction;

$-205 \ldots 350^{\circ} \mathrm{C}$ to isolate approx. $40 \%$ of heavy fraction.

In the course of the distillation, it was observed that visible soot amounts penetrated into the heavy fraction (Ambrosewicz-Walacik, Danielewicz 2015). The isolated, medium naphtha fraction was used for further study. The samples of diesel oil, rapeseed oil, industrial sample of TPO and naphtha fractions were analysed to determine viscosity at $40^{\circ} \mathrm{C}$ (pycnometric method), density at $15^{\circ} \mathrm{C}$ (EN ISO 3104:1994), acid value (EN 14104:2003), sulphur content (ISO 20884:2011), flash point (ISO 3679:2015), cold filter plug point (EN 116:2015) and oxidative stability (EN 14112:2016) (Table 1).

The medium naphtha fraction was selected for the composition of fuel blends. Prior to the appropriate examinations, pilot studies were conducted in order to determine a blend which would meet acceptable values of the analysed parameters according to the EN 590:2009 standard. Based on the selection of the added amount of pyrolytic oil, the value of the flash point, which determines the safety of fuel application, was considered in the first place. Sample DRP consisting of diesel oil, rapeseed oil and pyrolytic naphtha (volume ratio 40:55:5) was selected for engine tests because of its sufficiently high flash point $\left(>55^{\circ} \mathrm{C}\right)$. This sample was characterized with respect to the attributes, which were also determined for the initial samples. Moreover, in order to determine the impact of the addition of naphtha on the change in the physicochemical parameters of the sample, a two-component blend of diesel fuel and rapeseed oil was also composed, following which the characteristics were compared. Based on the conducted studies, it was demonstrated that the addition of a medium naphtha fraction favourably influenced the viscosity, density, and acid value of the analysed threecomponent blend in comparison to a two-component 
Table 1. Characteristics of rapeseed oil, TPO and naphtha fractions

\begin{tabular}{|c|c|c|c|c|c|c|c|c|}
\hline \multicolumn{2}{|c|}{ Samples } & $\begin{array}{c}\text { Viscosity at } 40^{\circ} \mathrm{C} \\
{\left[\mathrm{mm}^{2} / \mathrm{s}\right]}\end{array}$ & $\begin{array}{c}\text { Density at } \\
15^{\circ} \mathrm{C}\left[\mathrm{kg} / \mathrm{m}^{3}\right]\end{array}$ & $\begin{array}{c}\text { Acid value } \\
{[\mathrm{mg} \mathrm{KOH} / \mathrm{g}]}\end{array}$ & $\begin{array}{c}\text { Sulphur } \\
\text { content }[\mathrm{wt} \%]\end{array}$ & $\begin{array}{c}\text { Flash } \\
\text { point }\left[{ }^{\circ} \mathrm{C}\right]\end{array}$ & $\begin{array}{l}\text { Cold filter plug } \\
\text { point }\left[{ }^{\circ} \mathrm{C}\right]\end{array}$ & $\begin{array}{l}\text { Oxidative } \\
\text { stability }[\mathrm{h}]\end{array}$ \\
\hline \multicolumn{2}{|c|}{ Rapeseed oil } & 36.0 & 920 & 4.23 & 0.007 & $>200$ & n.d. & 6.52 \\
\hline \multicolumn{2}{|l|}{ TPO } & 5.68 & 955 & 4.33 & 0.49 & 53.0 & n.d. & $>27$ \\
\hline \multirow{3}{*}{$\begin{array}{l}\text { Naphtha } \\
\text { samples }\end{array}$} & light & 0.823 & 770 & 2.31 & 0.40 & $<3.5$ & $>-30$ & 0.5 \\
\hline & medium & 0.842 & 1003 & 3.07 & 0.60 & 12.0 & $>-30$ & $>27$ \\
\hline & heavy & 0.891 & 1360 & 3.78 & 0.85 & 25.0 & $>-30$ & $>27$ \\
\hline
\end{tabular}

Table 2. Characteristic of mixtures: DRP - volume ratio 40:55:5, DR - volume ratio 45:55 and MD

\begin{tabular}{|c|c|c|c|c|c|c|}
\hline Samples & $\begin{array}{c}\text { Density at } 40^{\circ} \mathrm{C} \\
{\left[\mathrm{mm}^{2} / \mathrm{s}\right]}\end{array}$ & $\begin{array}{c}\text { Viscosity at } 15^{\circ} \mathrm{C} \\
{\left[\mathrm{kg} / \mathrm{m}^{3}\right]}\end{array}$ & $\begin{array}{c}\text { Acid value } \\
{[\mathrm{mg} \mathrm{KOH} / \mathrm{g}]}\end{array}$ & $\begin{array}{c}\text { Sulphur content } \\
{[\mathrm{mg} / \mathrm{kg}]}\end{array}$ & $\begin{array}{c}\text { Cold filter plug } \\
\text { point }\left[{ }^{\circ} \mathrm{C}\right]\end{array}$ & $\begin{array}{c}\text { Oxidative } \\
\text { stability }[\mathrm{h}]\end{array}$ \\
\hline DRP & 11.42 & 865 & 0.68 & 272.5 & 1.0 & $>5.86$ \\
\hline DR & 17.82 & 875 & 0.81 & 6.12 & 5.0 & 9.25 \\
\hline MD & 2.73 & 827 & 0.07 & 0.006 & -1.0 & $>22$ \\
\hline
\end{tabular}

sample. However, it should be noted that despite a significant decrease in density of the three-component blend, the value of this parameter was approx. 2.5 times higher than the acceptable upper limit specified in EN 590:2009. The characteristic that did not meet the EN 590:2009 standard was the sulphur content, significantly exceeding the acceptable limit of $10 \mathrm{mg} / \mathrm{kg}$ (Table 2). Therefore, it is suggested that a desulfurization process of pyrolysis oil should be used before the distillation process.

\subsection{Engine test stand setup and methodology}

The engine tests were performed on a four-cylinder, CRDI engine (type - ADCR), provided by Andoria Motor Company, Poland. The engine is a mid-duty design designated for small cargo trucks and vans. Basic technical parameters of the engine have been presented in Table 3 .

Detailed information about the test engine and measurement shame can be found in earlier works by the authors of the present paper (Mikulski, Wierzbicki 2012; Mikulski et al. 2016). Here only selected information, necessary to assure proper understanding and repeatability of the research results, had been provided. The present research was conducted using standard EDC16C39 electronic controller with factory (optimized for diesel fuel operation) engine maps. It is important to highlight that the controller carries out two different fuel injection strategies, depending on the operation parameters. Under low loads in the medium speed range, divided injection was performed. In the remaining range, a single diesel fuel charge was injected in to the cylinder. Due to the fact that the tests were performed subsequently for fuel samples of radically different parameters, special care has been taken to ensure the reliability of the results. The fuel system, exhaust path and emission sampling paths were purged and flushed using designated procedures. For more information on the reliability assurance measures, refer to the work by Mikulski et al. (2016).
Table 3. Technical data of the ACDR engine by Andoria Motor Company

\begin{tabular}{|l|l|}
\hline \multicolumn{1}{|c|}{ Engine } & \multicolumn{1}{c|}{ ADCR } \\
\hline Type & $\begin{array}{l}\text { diesel, 4-stroke, turbocharged } \\
\text { with intercooler }\end{array}$ \\
\hline Fuel injection & CR fuel accumulator system \\
\hline Engine layout & 4-cylinder inline, vertical \\
\hline $\begin{array}{l}\text { Cylinder diameter / piston } \\
\text { travel }\end{array}$ & 94 / 95 mm \\
\hline Displacement volume & $2636 \mathrm{~cm}^{3}$ \\
\hline Compression ratio & $17.5: 1$ \\
\hline $\begin{array}{l}\text { Rated power / rotational } \\
\text { speed }\end{array}$ & $85 \mathrm{~kW} / 3700$ rpm \\
\hline $\begin{array}{l}\text { Max. torque / rotational } \\
\text { speed }\end{array}$ & $250 \mathrm{~N} \cdot \mathrm{m} / 1800 \ldots 2200 \mathrm{rpm}$ \\
\hline Min. idle rotational speed & $750 \mathrm{rpm}$ \\
\hline $\begin{array}{l}\text { Fuel consumption at } \\
\text { torque peak }\end{array}$ & $210 \mathrm{~g} / \mathrm{kWh}$ \\
\hline Injection system & $\begin{array}{l}\text { accumulator injection } \\
\text { system }(\mathrm{CR}) \text { Bosch CR2.0 }\end{array}$ \\
\hline Turbocharger & $\begin{array}{l}\text { radial, with exhaust extraction } \\
\text { valve }\end{array}$ \\
\hline EGR system & $\begin{array}{l}\text { pneumatic EGR valve with } \\
\text { exhaust cooler }\end{array}$ \\
\hline
\end{tabular}

During the tests, engine speed and dynamometer torque were set as demanded values and kept constant with accuracy of $\pm 10 \mathrm{rpm}$ and $\pm 5 \mathrm{~N} \cdot \mathrm{m}$ respectively. The cooling water and lube oil temperatures were also controlled to keep constant $85 / 95^{\circ} \mathrm{C} \pm 1{ }^{\circ} \mathrm{C}$. After stabilization was reached at the set operating point, steady state measurements were performed. The recording window of $120 \mathrm{~s}$ was set for data acquisition in every test run. In this period basic operation parameters of the engine, incylinder pressure, injector coil current, opacity and emissions were recorded. 
A piezoelectric pressure sensor (Type 6056A by Kistler), installed in the first cylinder through the heater plug adapter, was used for recording pressure signal. The recording was performed every $1 \mathrm{CA}$, in the full range of the engine's cycle. Pressure measurement results were then cycle-averaged, giving $p_{\text {avg }}(C A)$. Standard deviation was used to calculate the average error of pressure measurement for each crank angle $\Delta p_{\text {avg } \_r}(C A)$. The average relative error was then calculated:

$$
\Delta p_{\text {avg_r }}(C A)=\frac{\Delta p_{\text {avg }}(C A)}{p_{\text {avg }}(C A)} \cdot 100 \%
$$

as an estimate of the engine's operation repeatability in CA domain. For the determination of SOI, a current clamp has been used. The injector coil current signal was analysed in the same way as described for pressure signal.

The pressure signal was further analysed to designate combustion parameters. The calculated mean pressure traces were transformed using the Savitzky-Golay procedure to obtain smoothness of the $d p / d C A$ derivative signal, suitable for performing numerical calculations (Bromba, Ziegler 1981). Based on the smoothed pressure signals, apparent heat release rates were calculated. The calculations were made based on the equation of the first law of thermodynamics and equation of state for the closed part of the cycle from $C A_{1}=220$ (corresponding to IVC) to $C A_{2}=490$ (EVO). Based on the assumption that the change in the system energy caused by the injection of fuel is negligible and that the agent in the cylinder can be modelled as an ideal gas mixture, net HRR was calculated as:

$$
\operatorname{HRR}(\text { net })=\frac{\gamma}{\gamma-1} \cdot p \cdot \frac{d V}{d \alpha}+\frac{1}{\gamma-1} \cdot V \cdot \frac{d p}{d \alpha} .
$$

The calculations were performed adopting a constant ratio of specific heats according to Heywood $(\gamma=1.36)$ (Heywood 1988). Net HRR was further corrected by heat transfer to the cylinder walls, to give the gross HRR signal, which was presented in the results section. The mechanism of heat exchange was limited to convection, assuming a constant average wall temperature of $120^{\circ} \mathrm{C}$, with the heat transfer coefficient calculated according to the Hohenberg formula (Heywood 1988). The temperature of the agent in the cylinder was determined from the cylinder pressure for every CA using the equation of state. For this purpose mass of air aspired by the engine $G_{a i r}$, and inlet manifold temperature $T_{\text {air }}$ were used to determine IVC conditions. Those quantities were recorded during the tests, and time-averaged for each test run. Standard deviation was used to calculate the accuracy of all directly measured quantities. A similar methodology was used to determine the measurement uncertainty of concentration levels of exhaust components.

Furthermore, the method of second pressure derivative analysis was used in order to designate the SOC and to calculate the ignition delay angle $\alpha_{i d}$ (Mikulski, Wierzbicki 2016b). Volumetric efficiency $\eta_{v}$, BSFC and BSFCE were also calculated according to the following formulae:

$$
\eta_{v}=\frac{2 \cdot G_{a i r}}{\rho_{\text {air }} \cdot V_{d} \cdot N}
$$

$$
\begin{aligned}
& B S F C=\frac{G_{\text {fuel }}}{P_{e}} ; \\
& B S F C E=\frac{3600}{B S F C \cdot Q_{\text {fuel }}} .
\end{aligned}
$$

For the calculated values, the measurement uncertainty was designated using the Kline and McClintock (1953) method. The list of parameters recorded directly or indirectly during the test runs, along with maximum uncertainty for all measurement points, is presented in Table 4.

\section{Results and discussion}

The results were presented in Figures 1-23. For the selected fuel sample $\left(\mathrm{DRP}_{8}\right)$ an engine test plan was established. The results were compared with standard MD. For each of the fuels steady state measurements were performed for two rotational speeds and two injection strategies: $1500 \mathrm{rpm}$ divided injection strategy - pilot (10\% of total mass) + main injection, $3000 \mathrm{rpm}$ - single point injection strategy.

Based on the conducted engine studies, it was observed that at the beginning of the combustion process, the operation of the engine was the least stable, which was considered normal because of the high sensitivity of kinetic mechanisms to changing conditions in the intake manifold. Furthermore, it was demonstrated that regardless of the implemented strategy of fuel injection (single or sequential), the largest difference in the unrepeatability of engine operation was observed at its low loads (Figures $1,4)$. In order to explain the phenomenon described, the results were compared to the fuel injection waveform and in-cylinder pressure traces (Figures 7, 11). Namely, the injection process imaged by the injector excitation current for measuring points $1500 / 50$ and $3000 / 50$ always ended before the beginning of the combustion process. This means that the combustion process took place in an environment of partially premixed fuel, resulting in its more uncontrolled character due to the predominance of kinetic mechanisms. For higher engine loads (visible for the measuring points $1500 / 150,1500 / 200$ and 3000/150, $3000 / 200$ ), combustion started during the injection of the basic fuel dose, which caused the combustion process to be dominated by flame propagation and significantly conditioned by the injection process (controlled directly by the engine controller) (Figures 2, 3, 5, 6).

Given the analysed fuel mixtures, it was demonstrated that the highest unrepeatability of engine operation was observed when it was fed with a DRP sample, containing $40 \%$ of diesel oil, $55 \%$ of rapeseed oil and $5 \%$ of pyrolytic naphtha in its composition. However, it is worth noting that in none of the cases the repeatability of the cycles (determined as covariance of mean indicated pressure) exceeded $5 \%$, which means that the combustion process was conducted in a controlled manner. Additionally, no misfires or signs of knocking combustion were observed. On the other head, the most stable engine operation was demonstrated when it was fed with diesel fuel. 
Table 4. List of parameters recorded directly and derived indirectly from calculation, along with achieved maximum uncertainty

\begin{tabular}{|c|c|c|c|c|c|}
\hline \multicolumn{6}{|c|}{ Directly measured } \\
\hline No & Parameter & Symbol & Measurement device & Uncertainty level & Unit \\
\hline 1 & Engine rotational speed & $N$ & \multirow[t]{3}{*}{ AVL DP 240} & \pm 5 & $\mathrm{rpm}$ \\
\hline 2 & Torque & $T_{e}$ & & \pm 2 & $\mathrm{~N} \cdot \mathrm{m}$ \\
\hline 3 & Generated Power & $P_{e}$ & & \pm 0.2 & $\mathrm{~kW}$ \\
\hline 4 & Air aspired to the engine & $G_{\text {air }}$ & SENSYFLOW P & \pm 0.5 & $\mathrm{~kg} / \mathrm{h}$ \\
\hline 5 & Fuel consumption & $G_{f u e l}$ & AVL 735S & \pm 0.1 & $\mathrm{~kg} / \mathrm{h}$ \\
\hline 6 & Intake Air temperature & $T_{\text {air }}$ & PT 100 & \pm 0.2 & $\mathrm{~K}$ \\
\hline 7 & Start of injection angle & SOI & Current clamp & \pm 0.5 & $\mathrm{CA}$ \\
\hline 8 & Total hydrocarbons * & THC & \multirow[t]{5}{*}{ AVL AMA i60 } & \pm 11 & ppm \\
\hline 9 & Total nitrogen oxides * & $\mathrm{NO}_{\mathrm{x}}$ & & \pm 19 & ppm \\
\hline 10 & Carbon monoxide * & $\mathrm{CO}$ & & \pm 13 & ppm \\
\hline 1 & Carbon dioxide ${ }^{*}$ & $\mathrm{CO}_{2}$ & & \pm 1 & ppt \\
\hline 10 & Oxygen * & $\mathrm{O}_{2}$ & & \pm 1 & ppt \\
\hline 13 & Opacity & EGO & AVL 439 & \pm 0.9 & $\%$ \\
\hline \multicolumn{6}{|c|}{ Calculated } \\
\hline 14 & Start of combustion angle & SOC & $\begin{array}{l}\text { Second derivative of } \\
\text { pressure analysis }\end{array}$ & \pm 1 & $\mathrm{CA}$ \\
\hline 15 & Heat release rate & HRR & Equation (2) & - & $\mathrm{J} / \mathrm{CA}$ \\
\hline 16 & Volumetric efficiency & $\eta_{v}$ & Equation (3) & \pm 1 & $\%$ \\
\hline 17 & Brake specific fuel consumption & BSFC & Equation (4) & \pm 10 & $\mathrm{~g} / \mathrm{kWh}$ \\
\hline 18 & $\begin{array}{l}\text { Brake specific fuel conversion } \\
\text { efficiency }\end{array}$ & BSFCE & Equation (5) & \pm 1 & $\%$ \\
\hline
\end{tabular}

Note: ${ }^{\star}$ - concentration of the compound in the exhaust gases.

As it can be seen in Figures 7-9, the type of applied fuel significantly affected the course of combustion processes, which consequently caused significant changes in the selection of control parameters, executed by the engine controller. The controlled parameters included fuel injection (start, and duration) (Figures 7-9), as well as, by controlling a turbine, parameters mass of air aspired into the cylinder, which is visible on the pressure traces during the compression phase (Figures 9-11).

Analyses of pressure traces and heat release rates provide important information about the trends in combustion demonstrated by the tested DRP sample as compared to diesel fuel. At the rotational speed of $3000 \mathrm{rpm}$ the volumetric efficiency was always slightly higher for DRP than for diesel fuel, which is manifested by a higher pressure achieved in the compression phase (Figures 10-12).

The disproportion increased with the increase in load and this effect was accompanied by a shift in SOI point of diesel fuel towards BDC (max. 3 CA at max. load). The earlier injection resulted in a proportional shift of ignition point and thus significantly higher $P_{\max }$ achieved by the engine fed with DRP in comparison to diesel fuel at the same operating points. For a single injection, combustion characteristics of both fuels were similar. The HRR traces for both fuels in these cases demonstrated similar maximum values. A slightly accelerated ignition of DRP in comparison to diesel oil, observed despite identical injection characteristics for an operating point of $3000 \mathrm{rpm} / 50 \mathrm{~N} \cdot \mathrm{m}$, can be explained by higher in-cylinder pressure achieved at the time of injection. The ignition delay is significantly correlated with thermodynamic parameters of the load during the process of liquid fuel injection (Mikulski, Wierzbicki 2016a).

The analysis of the combustion process for the case of a sequential fuel injection performed at a rotational speed of $1500 \mathrm{rpm}$ (Figures 7-9) seems interesting. In this case, no major disproportion in volumetric efficiency was observed, while the reaction of the engine controller during injection process was similar to the previously described single injection cases. For higher loads, an earlier DRP injection was observed both in the case of pilot and main dose. Furthermore, the control range for the pilot dose was significantly broader. The course of the combustion process itself seems very interesting. Based on the analysis of heat release rates for diesel fuel (Figures 7-10), regardless of the load, it can be observed that a small pilot dose underwent ignition substantially before TDC, and that its combustion process ended before the start of main dose injection (except for the lowest test loads $-50 \mathrm{~N} \cdot \mathrm{m}$, for which the injection of the main dose started in the phase of afterburning of the pilot dose), at the same time preparing the conditions for its ignition. For DRP, in none of the test cases, despite the same or earlier injection point of the initializing dose as compared to the diesel fuel, no increase 
in HRR before TDC was observed. The entire amount of the injected fuel underwent ignition during the injection of the main dose. At the same time, it translated into increased ignition delay, but only for very low loads (up to $125 \mathrm{~N} \cdot \mathrm{m})$. In the remaining cases, the SOC of the main dose for both fuels was maintained at the same level as a result of an earlier injection of DRP. A significantly de-

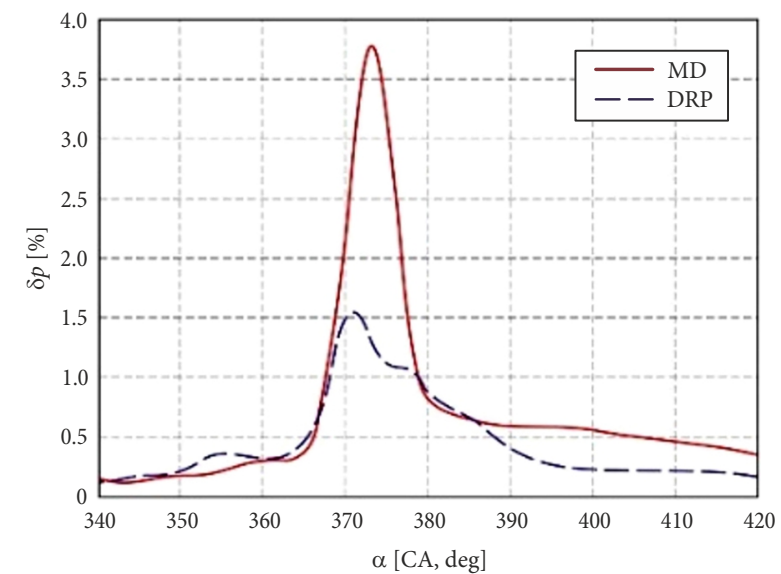

Figure 1. Mean cycle-by-cycle differences in cylinder pressure vs CA for MD and DRP (1500 rpm / $50 \mathrm{~N} \cdot \mathrm{m})$

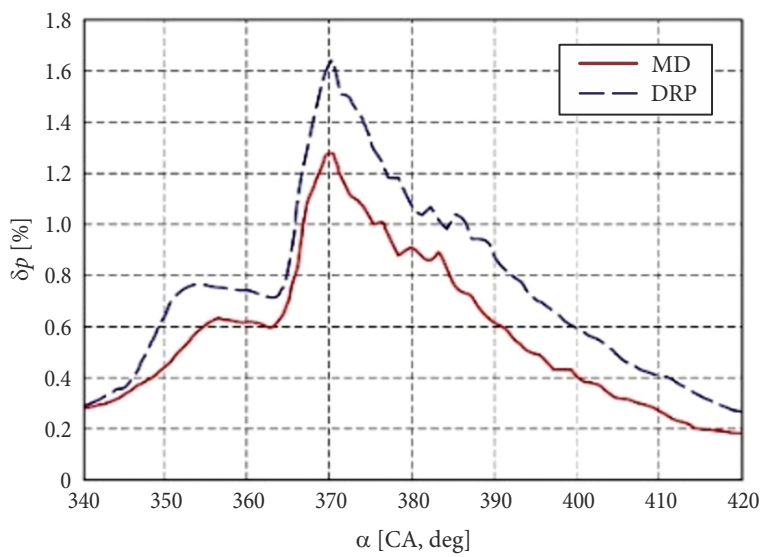

Figure 2. Mean cycle-by-cycle differences in cylinder pressure vs CA for MD and DRP (1500 rpm / $150 \mathrm{~N} \cdot \mathrm{m}$ )

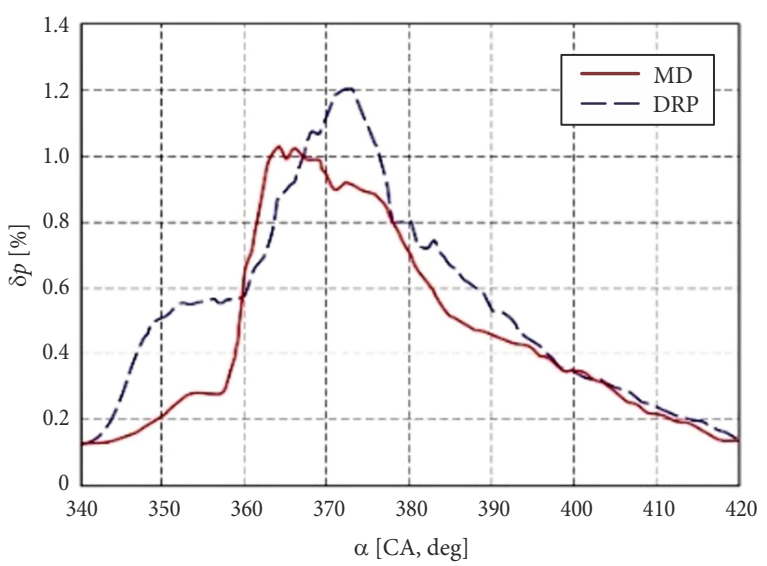

Figure 3. Mean cycle-by-cycle differences in cylinder pressure vs CA for MD and DRP (1500 rpm / $200 \mathrm{~N} \cdot \mathrm{m})$ layed initial ignition point clearly correlates with increased concentration of unburned HCs and decrease in the concentration of $\mathrm{NO}_{\mathrm{x}}$ (Figure 16) in case of supplying the engine with DRP fuel for low loads at a rotational speed of $1500 \mathrm{rpm}$. When the engine achieved torque higher than $150 \mathrm{~N} \cdot \mathrm{m}$ (Figure 9), with the SOC maintained at the same level for both fuels by controlling the start of the injection,

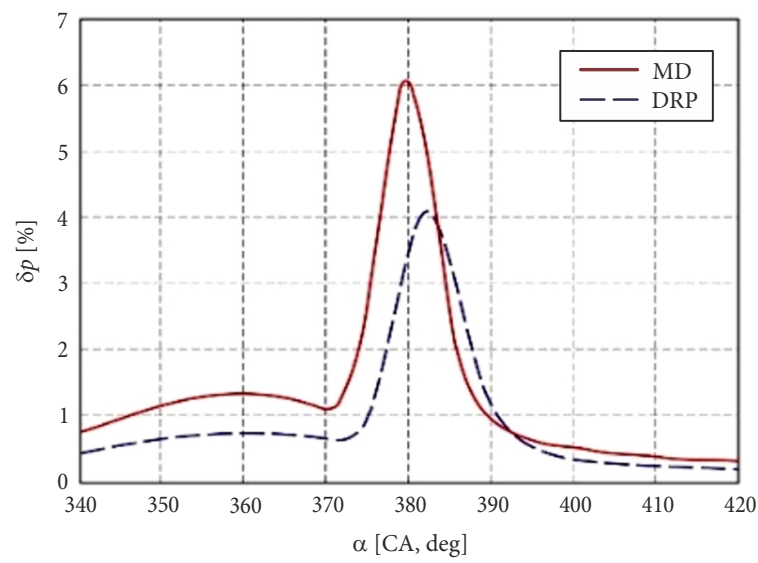

Figure 4. Mean cycle-by-cycle differences in cylinder pressure vs CA for MD and DRP (3000 rpm / $50 \mathrm{~N} \cdot \mathrm{m}$ )

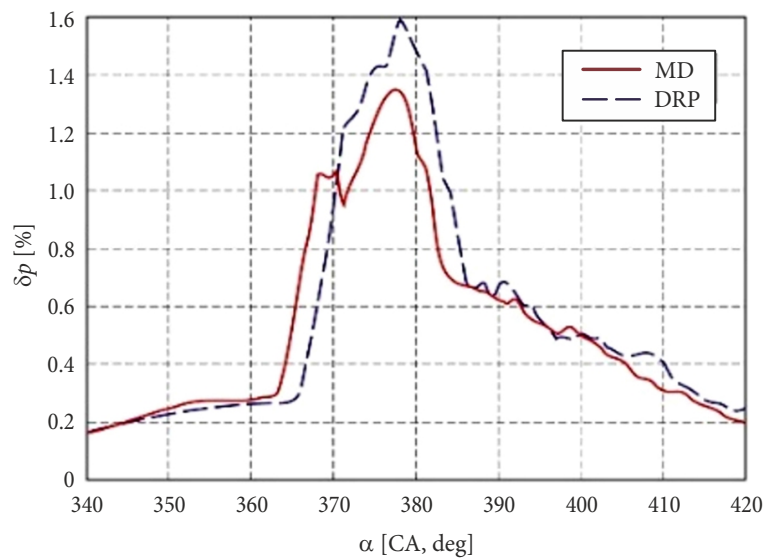

Figure 5. Mean cycle-by-cycle differences in cylinder pressure vs CA for MD and DRP (3000 rpm / $150 \mathrm{~N} \cdot \mathrm{m}$ )

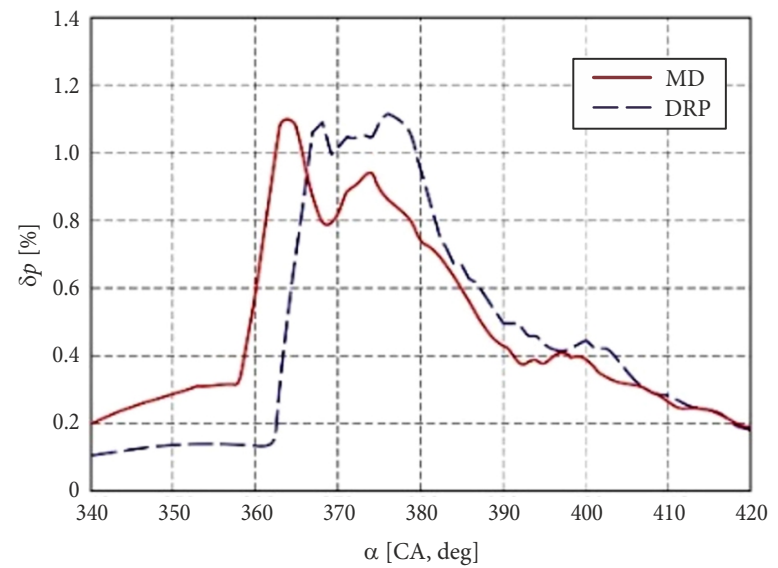

Figure 6. Mean cycle-by-cycle differences in cylinder pressure vs CA for MD and DRP (3000 rpm / $200 \mathrm{~N} \cdot \mathrm{m}$ ) 
a cumulative effect occurred in the case of DRP - the pilot and main dose were burned simultaneously, generating higher rates of heat release as compared to diesel fuel. This resulted in higher values of maximum pressure and correlated with increased emissions of $\mathrm{NO}_{\mathrm{x}}$ (Figure 16).

The engine volumetric efficiency changed significantly with the supplied fuel (Figure 13). The largest differences

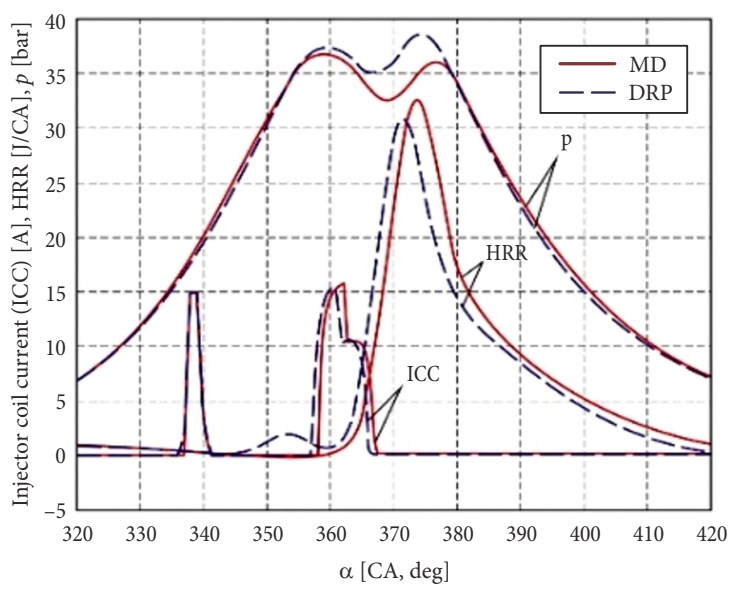

Figure 7. Injection current vs CA for $\mathrm{MD}$ and DRP $(1500 \mathrm{rpm} / 50 \mathrm{~N} \cdot \mathrm{m})$

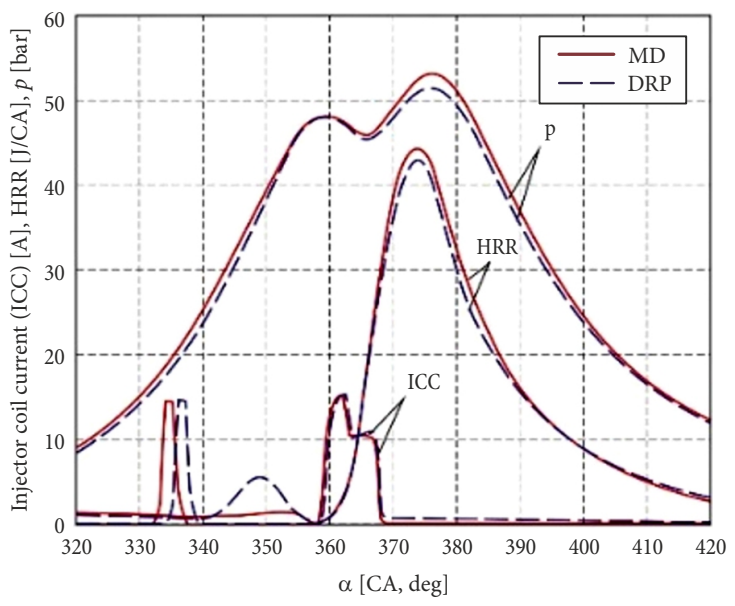

Figure 8. Injection current vs CA for $\mathrm{MD}$ and DRP $(1500 \mathrm{rpm} / 150 \mathrm{~N} \cdot \mathrm{m})$

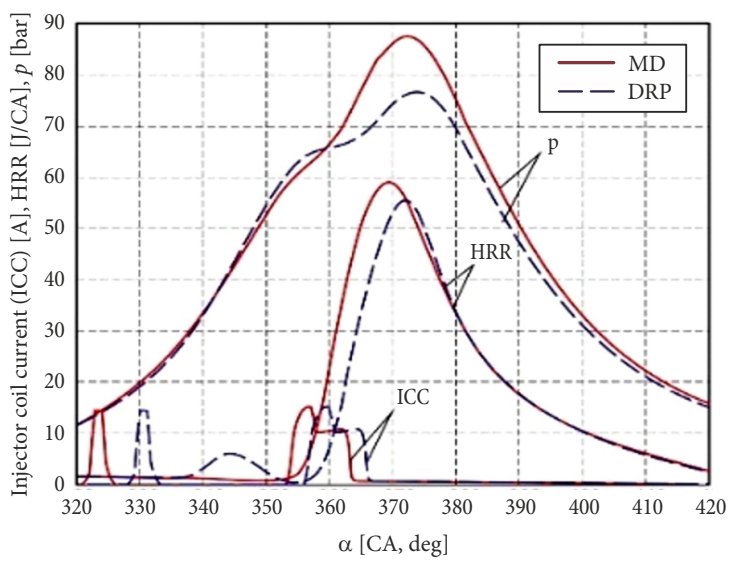

Figure 9. Injection current vs CA for MD and DRP $(1500 \mathrm{rpm} / 200 \mathrm{~N} \cdot \mathrm{m})$ were observed for $1500 \mathrm{rpm}$, where the turbocharger engaging point is clearly visible for DRP fuel sample. At the same point, MD sample operation was realized at much lower volumetric efficiency. Generally, DRP operation was characterized by higher volumetric efficiencies in the whole investigated load spectrum.

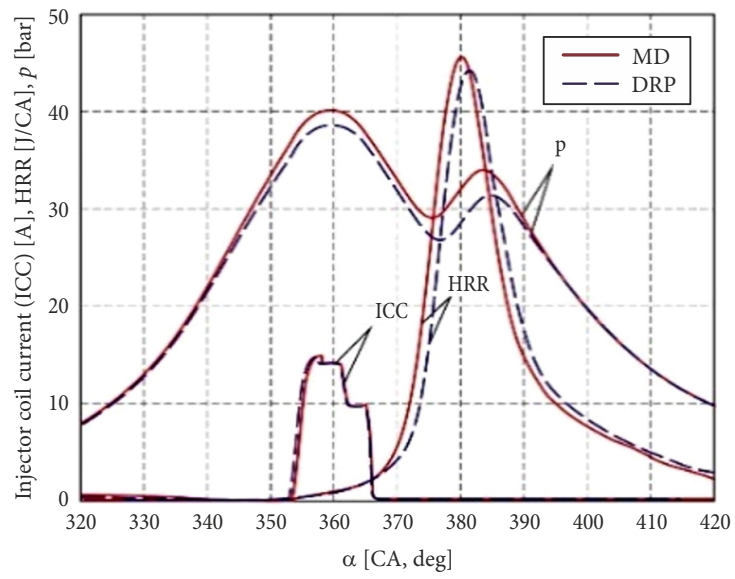

Figure 10. Injection current vs CA for MD and DRP (3000 rpm / $50 \mathrm{~N} \cdot \mathrm{m})$

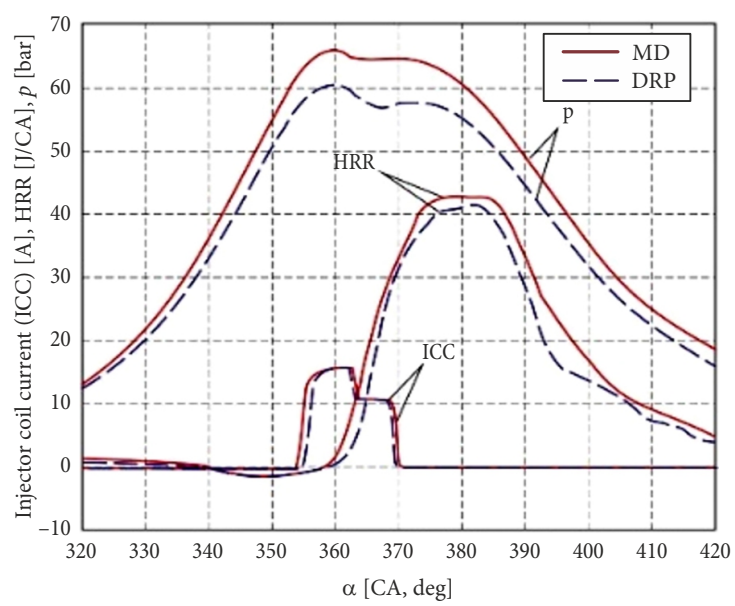

Figure 11. Injection current vs CA for $\mathrm{MD}$ and DRP (3000 rpm / $150 \mathrm{~N} \cdot \mathrm{m})$

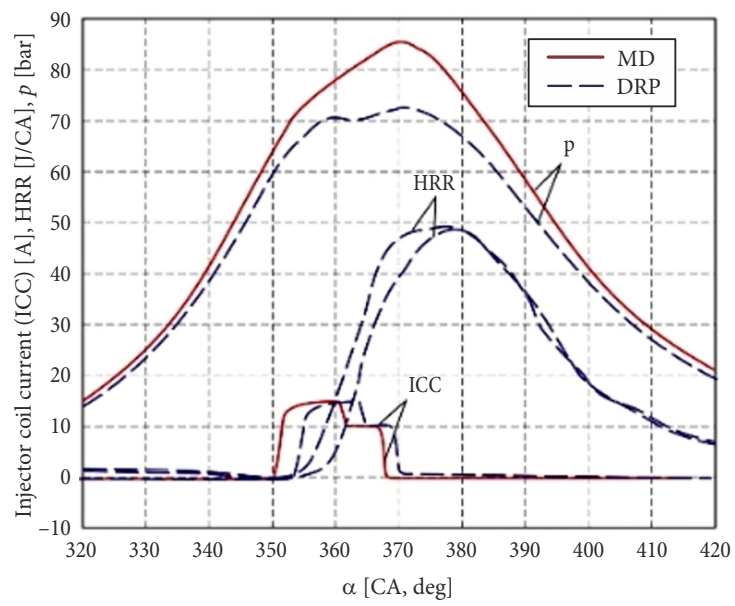

Figure 12. Injection current vs CA for MD and DRP (3000 rpm / $200 \mathrm{~N} \cdot \mathrm{m}$ 
The clear trend of reducing BSFC with engine load (Figure 14) recognizable for both fuels was associated with decreasing friction / break power ratio. For $1500 \mathrm{rpm}$ BSFC was always higher for DRP when compared to MD sample. This was mainly due to lower heating value of the DRP sample, which was $40.1 \mathrm{MJ} / \mathrm{kg}$ compared to

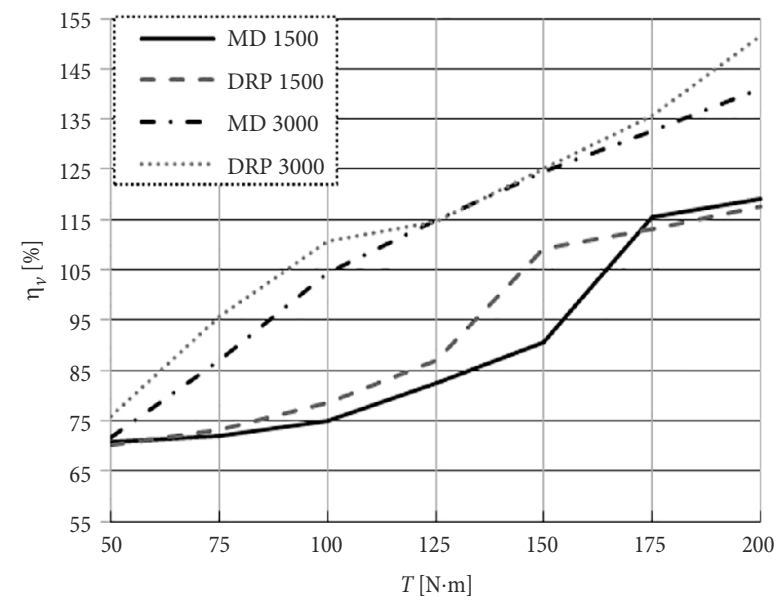

Figure 13. Volumetric efficiency $\eta_{v}$ vs engine load for MD and DRP at $1500 \mathrm{rpm}$ and $3000 \mathrm{rpm}$

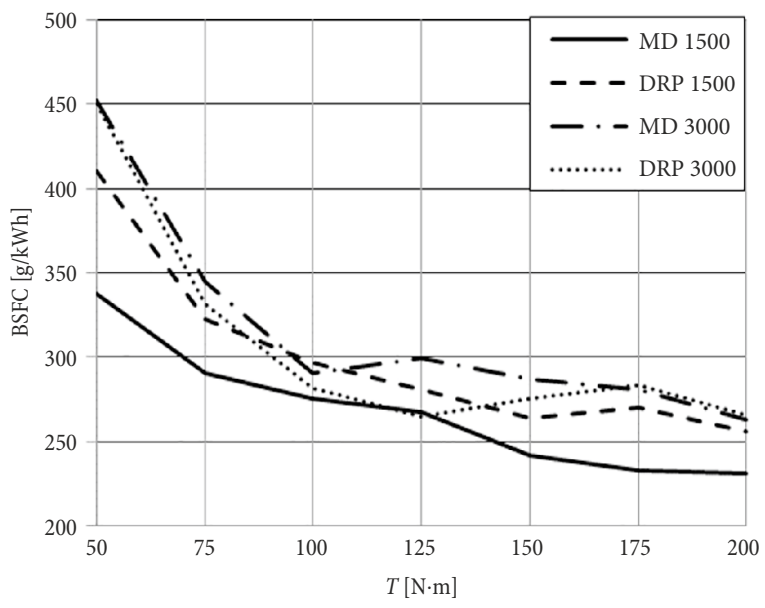

Figure 14. BSFC vs engine load for MD and DRP at $1500 \mathrm{rpm}$ and $3000 \mathrm{rpm}$

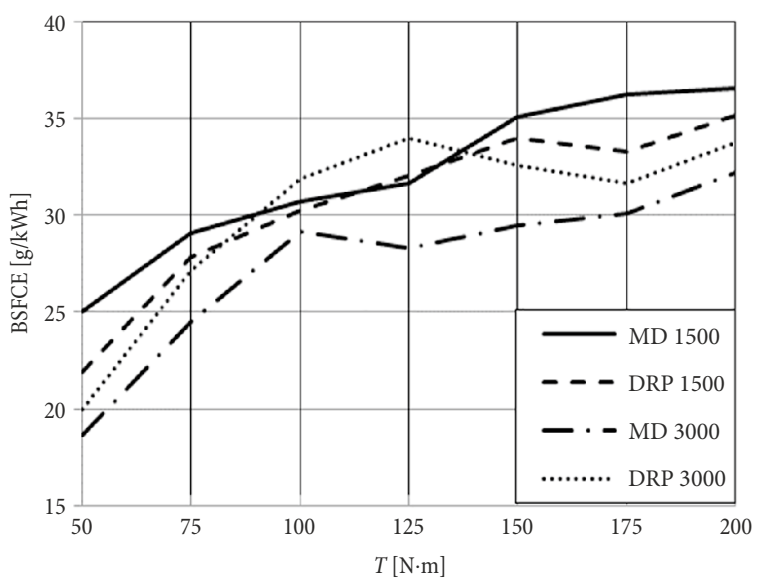

Figure 15. BSFCE vs engine load for MD and DRP at $1500 \mathrm{rpm}$ and $3000 \mathrm{rpm}$
42.6 MJ $/ \mathrm{kg}$ of the tested diesel fuel. However, for $3000 \mathrm{rpm}$ DRP fuel consumption measurements resulted in lower values compared to MD. This suggests big differences in fuel conversion efficiencies favouring the alternative fuel. BSFCE results were plotted on Figure 15. This shows clearly that DRP resulted in much more efficient engine operation at higher rpms. The maximum observed difference was close to $5 \%$ at $125 \mathrm{~N} \cdot \mathrm{m}$. For lower rotational speeds (1500 rpm) BSFC of DRP was at the same level or lower when compared to $\mathrm{MD}$. The main reason for that was the pre-ignition of the pilot dose, which resulted in increased pressure before TDC. This was not observed for the diesel fuel operation. Despite DRP proved to be able to provide more efficient operation in some operating points, best point efficiency was still achieved on diesel fuel $(36.5 \%$ at $1500 \mathrm{rpm} / 200 \mathrm{~N} \cdot \mathrm{m})$. Never less, the results suggest that there is a big room for efficiency improvement for DRP, when the engine map would be optimized for such fuel. Especially divided injection strategy proves less useful at this case due to better auto-ignition properties of DRP resulting in early firing of the injected pilot dose.

Based on the analysis of exhaust gas emissions, it was observed that in the load range from 50 to $150 \mathrm{~N} \cdot \mathrm{m}$ and $1500 \mathrm{rpm}$ the THC concentration was significantly higher in the case of DRP sample in comparison to the MD sample. In turn, in the measuring points above $150 \mathrm{~N} \cdot \mathrm{m}$, the THC emissions remained on the same level for both tested fuels (Figures 16, 17). The more than double concentration of unburned HCs for the lowest loads correlates with a significantly delayed ignition of the main DRP dose, caused by the lack of initial dose ignition. As a result, the entire ignition process is shifted towards EVO and at the same time significantly slows down due to temperature decrease in the expansion phase, leading to partially unburned fuel. The described effect is gradually eliminated by the engine controller during load increase by earlier fuel injection performed for DRP operation. At the test point of $150 \mathrm{~N} \cdot \mathrm{m} / 1500 \mathrm{rpm}$, both the SOI and the course of heat release rate for both MD and DRP tests are similar, which correlates with a similar concentration of THC.

In the case of engine operation at a speed of $3000 \mathrm{rpm}$ it was observed that for the loads up to $75 \mathrm{~N} \cdot \mathrm{m}$, the concentration of THC in the exhaust gas is higher when the DRP sample is burned, whereas above this measuring point, it is similar for both samples. In this case, for the minimum load, the SOI is maintained at a similar level, which was achieved thanks to higher charging pressures, but despite this, an increased concentration of THC was observed (Figures 18, 19).

At $1500 \mathrm{rpm}$ in the load range from 50 to $100 \mathrm{~N} \cdot \mathrm{m}$, MD engine operation was characterized by slightly larger EGO than for DRP sample. However, above the measuring point of $100 \mathrm{~N} \mathrm{~m}$, DRP sample operation resulted in very high opacity, which reached the maximum of $20 \%$ at $150 \mathrm{~N} \cdot \mathrm{m}$. This correlated with accelerated combustion observed due to lack of pilot dose ignition, and proves along with the efficiency drop that sequential injection is not the best option for DRP engine operation. The EGO 
for MD and DRP were equalized again for $175 \mathrm{~N} \cdot \mathrm{m}$ case. For engine operation at $3000 \mathrm{rpm}$ now significant disproportions in EGO were observed, however it should be emphasized that the opacity for DRP increased faster with increasing load.

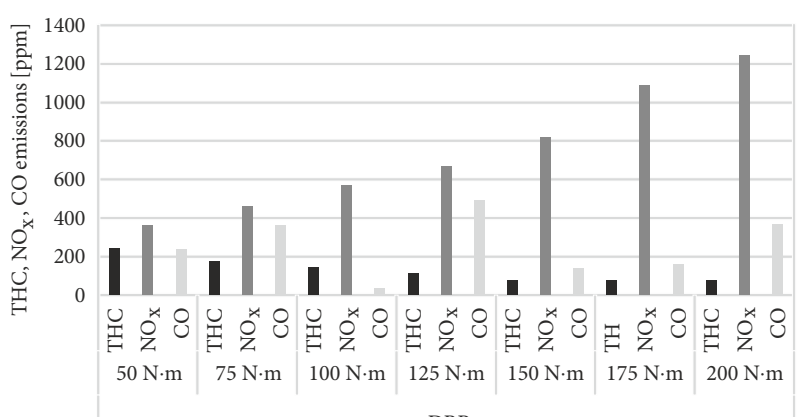

DRP

Figure 16. Emission of THC, $\mathrm{NO}_{\mathrm{x}}$ and $\mathrm{CO}$ for DRP sample with operating parameters of engine $1500 \mathrm{rpm}$

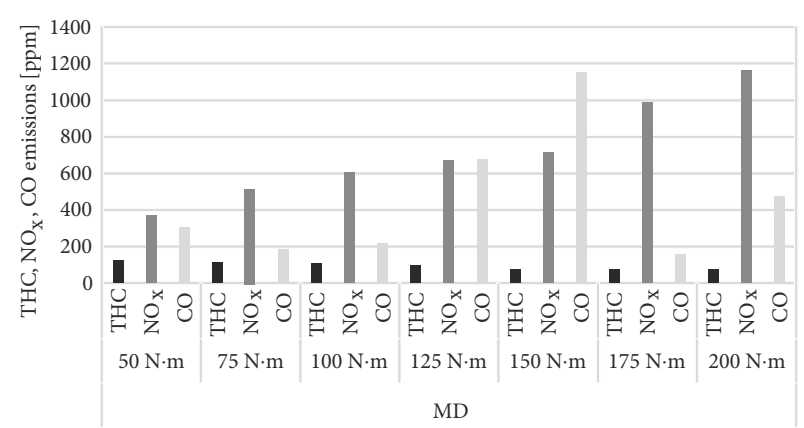

Figure 17. Emission of THC, $\mathrm{NO}_{\mathrm{x}}$ and $\mathrm{CO}$ for $\mathrm{MD}$ sample with operating parameters of engine $1500 \mathrm{rpm}$

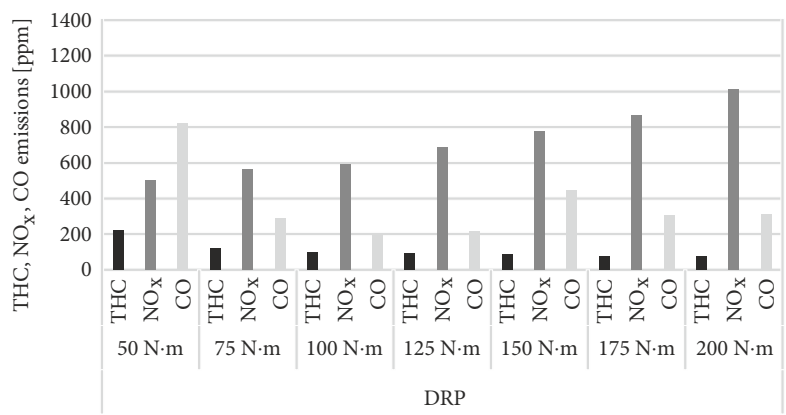

Figure 18. Emission of THC, $\mathrm{NO}_{\mathrm{x}}$ and $\mathrm{CO}$ for DRP sample with operating parameters of engine $3000 \mathrm{rpm}$

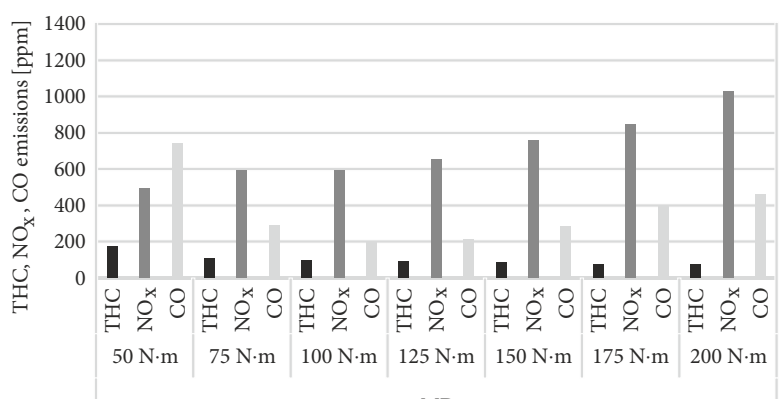

MD

Figure 19. Emission of THC, $\mathrm{NO}_{\mathrm{x}}$ and $\mathrm{CO}$ for MD sample with operating parameters of engine $3000 \mathrm{rpm}$
The study of $\mathrm{CO}_{2}$ concentration in exhaust gas resulting from combustion of fuels in the engine operating at a speed of $1500 \mathrm{rpm}$ demonstrated that in the load range from 50 to $125 \mathrm{~N} \cdot \mathrm{m}$, both a commercial MD sample and DRP sample generated similar quantities of this compound. Significant differences in the level of $\mathrm{CO}_{2}$ were recorded in a further measuring point from 125 to $175 \mathrm{~N} \cdot \mathrm{m}$, in which the concentration of the compound increased in the case of the MD sample combustion and decreased for the fuel blend (Figures 20, 21). Exhaust gas produced during the combustion of both analysed samples in the engine operating at maximum speed was characterized by similar concentrations of $\mathrm{CO}_{2}$ and $\mathrm{NO}_{\mathrm{x}}$ (Figures 18, $19,22,23)$. However, it is worth noting, that under engine operating conditions of $1500 \mathrm{rpm}$ and low loads, the DRP sample was characterized by a higher concentration of $\mathrm{NO}_{\mathrm{x}}$, which with the increase of the load became substantially identical to the concentration recorded for the MD fuel.

Referring to the results obtained for the MD sample it is noteworthy that for the test conditions of $1500 \mathrm{rpm}$ and $150 \mathrm{~N} \cdot \mathrm{m}$, the reference sample was characterized by the highest concentration of $\mathrm{CO}_{2}$ and the lowest concentration of $\mathrm{NO}_{\mathrm{x}}$, which correlates with volumetric efficiency patterns (Figure 13), which in this case was significantly higher for DRP sample $\left(\eta_{v M D}=90 \%\right.$, DRP sample approx. $110 \%)$. In the case of the engine operating conditions with the use of the reference sample at a speed of $3000 \mathrm{rpm}$, the resulting exhaust gas was characterized by the highest $\mathrm{CO}_{2}$ concentration (Figure 23) and, within the major

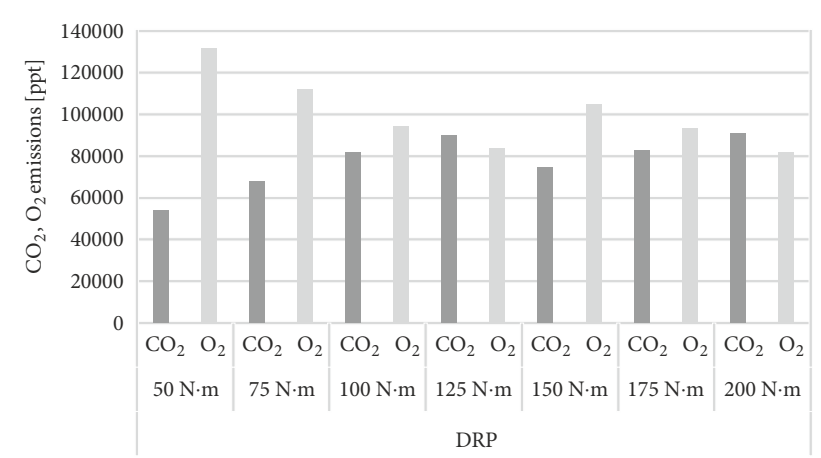

Figure 20. Emission of $\mathrm{CO}_{2}$ and $\mathrm{O}_{2}$ for DRP sample with operating parameters of engine $1500 \mathrm{rpm}$

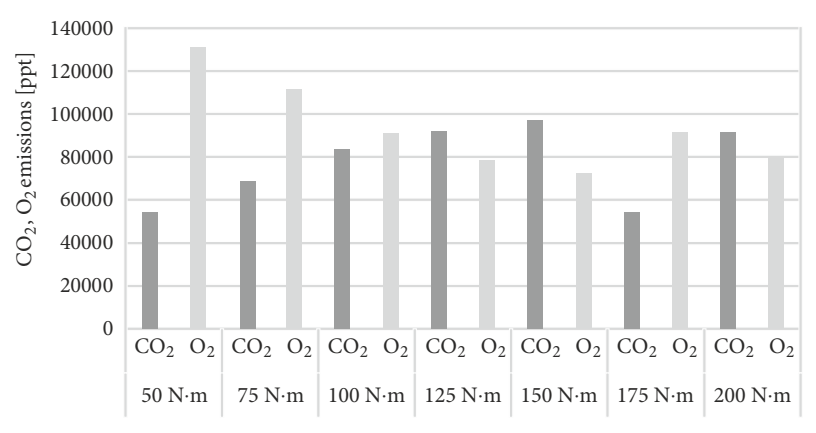
MD

Figure 21. Emission of $\mathrm{CO}_{2}$ and $\mathrm{O}_{2}$ for $\mathrm{MD}$ sample with operating parameters of engine $1500 \mathrm{rpm}$ 
part of the study range, by the lowest THC concentration (Figure 19). The obtained results of exhaust gas emission tests indicate accurate, complete combustion of the fuel, and an appropriate selection of control parameters of the combustion process for this sample.

Analysis of $\mathrm{CO}$ concentration at engine speeds of both $1500 \mathrm{rpm}$ and $3000 \mathrm{rpm}$ demonstrated an unequal nature of generation of this compound in different load ranges (Figures 22, 23). Generally, it was demonstrated that both in the highest and the lowest measuring points (50 and $200 \mathrm{~N} \cdot \mathrm{m}$ ) for a speed of $1500 \mathrm{rpm}$ and $200 \mathrm{~N} \cdot \mathrm{m}$ for $3000 \mathrm{rpm}$, the highest amounts of this compound were formed during the combustion of the MD sample. On the other hand, during operation of the engine at a speed of $1500 \mathrm{rpm}$ at a minimum and maximum load, a lower level of this compound was observed for the DRP sample. However, it is noteworthy that for both the MD sample and the DRP sample burned in the engine operating at a speed of $1500 \mathrm{rpm}$ in the load range from 100 to $200 \mathrm{~N} \cdot \mathrm{m}$, the trend of changes in the $\mathrm{CO}$ content in the exhaust gas had a similar shape. However, a contrary situation was recorded for the samples burned in the engine operating at maximum speed.

\section{Conclusions}

It was proven that the addition of pyrolytic oil fraction can improve some basic drawbacks of crude rapeseed oil / diesel mixtures like high density and viscosity or low cold filter plugging point. The research confirmed the assumption that the ternary mixture of mineral oil (diesel), crude rapeseed oil and fraction of pyrolytic oil is suitable for modern CI engines. Moreover, it was demonstrated that the selected mixture was characterized by a similar or lower specific fuel consumption compared to standard diesel, except the cases were sequential injection was incorporated. At this operating mode, fuel conversion efficiency was drastically decreased and correlated with increased THC emissions. THC concentration in the exhaust gas during engine operation at $1500 \mathrm{rpm}$ in the load range from 50 to $150 \mathrm{~N} \cdot \mathrm{m}$ was significantly higher in the case of the combustion of the DRP sample, which correlated with a significantly delayed ignition of the main injected fuel dose caused by the lack of ignition of the initial dose.

As a result, the entire ignition process was shifted towards EVO and at the same time significantly slowed down due to temperature decrease in the expansion phase, leading to partially unburned fuel. In the case of engine operation at $1500 \mathrm{rpm}$ and $3000 \mathrm{rpm}$, above the abovementioned measuring points, THC concentration was similar for both samples.

Analysis of EGO and $\mathrm{CO}_{2}$ concentration demonstrated that the DRP sample was characterized by a higher EGO and lower $\mathrm{CO}_{2}$ concentration during the combustion in the engine operating at a speed of $1500 \mathrm{rpm}$ in the range above $100 \mathrm{~N} \cdot \mathrm{m}$. For the engine operation at a speed of $3000 \mathrm{rpm}$ it was demonstrated that generally, EGO, $\mathrm{CO}_{2}$ and $\mathrm{NO}_{\mathrm{x}}$ were at similar levels, in measuring points from

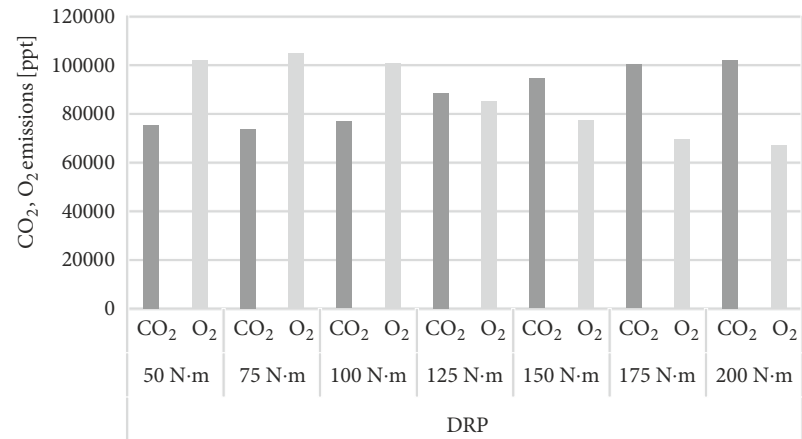

Figure 22. Emission of $\mathrm{CO}_{2}$ and $\mathrm{O}_{2}$ for DRP sample with operating parameters of engine $3000 \mathrm{rpm}$

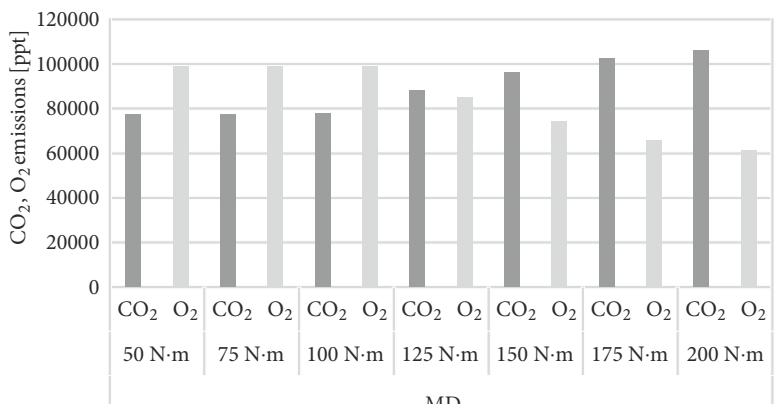

MD

Figure 23. Emission of $\mathrm{CO}_{2}$ and $\mathrm{O}_{2}$ for $\mathrm{MD}$ sample with operating parameters of engine $3000 \mathrm{rpm}$

50 to $125 \mathrm{~N} \cdot \mathrm{m}$, while above $125 \mathrm{~N} \cdot \mathrm{m}$ opacity and $\mathrm{CO}_{2}$ concentration slowly increased for the three-component sample. Observations made for the engine operating at both rotational speeds lead to the conclusion that a more difficult auto-ignition and extended combustion recorded for the DRP blend were most probably caused by still higher viscosity and density compared to mineral diesel. This also resulted in the fact that at the same injection pressure, a deterioration of fuel atomization occurred. However, the measurements indicate that this effect can be effectively mitigated by controlling the injection characteristics (both the initial ignition point and the injection pressure).

Generally, based on the conducted tests, it was found that the strategy of sequential injection itself, which was proven useful in case of MD, was not an effective method for reducing emissions for the analysed DRP sample.

\section{Contribution}

The manuscript was written through contributions of all authors.

All authors have given approval to the final version of the manuscript.

\section{Funding}

Research were supported by the University funds, without an external support.

\section{Disclosure statement}

There are no conflicts of interest to disclose. 


\section{References}

Adrados, A.; de Marco, I.; Caballero, B. M.; López, A.; Laresgoiti, M. F.; Torres, A. 2012. Pyrolysis of plastic packaging waste: a comparison of plastic residuals from material recovery facilities with simulated plastic waste, Waste Management 32(5): 826-832. https://doi.org/10.1016/j.wasman.2011.06.016

Agarwal, D.; Kumar, L.; Kurmar Agarwal, A. 2008. Performance evaluation of a vegetable oil fuelled compression ignition engine, Renewable Energy 33(6): 1147-1156.

https://doi.org/10.1016/j.renene.2007.06.017

Ambrosewicz-Walacik, M.; Danielewicz, T. 2015. Pyrolytic oil and petroleum fractions obtained by pyrolysis of vehicle tires as an energy sources for compression-ignition engines, Combustion Engines 162(3): 952-957.

Atabani, A. E.; Silitonga, A. S.; Badruddin, I. A.; Mahlia, T. M. I.; Masiuki, H. H.; Mekhilef, S. 2012. A comprehensive review on biodiesel as an alternative energy resource and its characteristics, Renewable and Sustainable Energy Reviews 16(4): 2070-2093. https://doi.org/10.1016/j.rser.2012.01.003

Bridgwater, A. V.; Canales, A. J. A. 2013. Bio-fuel Composition and Method for Manufacture of Bio-Fuel Composition. Patient WO 2013027050 A1. Aston University, UK. Available from Internet: https://www.google.com/patents/ WO2013027050A1?cl=en22

Bromba, M. U. A.; Ziegler, H. 1981. Application hints for Savitzky-Golay digital smoothing filters, Analytical Chemistry 53(11): 1583-1586. http://dx.doi.org/10.1021/ac00234a011

Butler, E.; Devlin, G.; Meier, D.; McDonnell, K. 2011. A review of recent laboratory research and commercial developments in fast pyrolysis and upgrading, Renewable and Sustainable Energy Reviews 15(8): 4171-4186. https://doi.org/10.1016/j.rser.2011.07.035

Delattre, C.; Forissier, M.; Pitault, I.; Schweich, D.; Bernard, J. R. 2001. Improvement of the microactivity test for kinetic and deactivation studies involved in catalytic cracking, Chemical Engineering Science 56(4): 1337-1345. https://doi.org/10.1016/S0009-2509(00)00356-0

Doğan, O.; Çelik, M. B.; Özdalyan, B. 2012. The effect of tire derived fuel/diesel fuel blends utilization on diesel engine performance and emissions, Fuel 95: 340-346. https://doi.org/10.1016/j.fuel.2011.12.033

EN 116:2015. Diesel and Domestic Heating Fuels. Determination of Cold Filter Plugging Point. Stepwise Cooling Bath Method.

EN 590:2009. Automotive Fuels - Diesel - Requirements and Test Methods.

EN 14104:2003. Fat and Oil Derivatives. Fatty Acid Methyl Esters (FAME). Determination of Acid Value.

EN 14112:2016. Fat and Oil Derivatives. Fatty Acid Methyl Esters (FAME). Determination of Oxidation Stability (Accelerated Oxidation Test).

EN ISO 3104:1994. Petroleum Products - Transparent and Opaque Liquids - Determination of Kinematic Viscosity and Calculation of Dynamic Viscosity.

Heywood, J. B. 1988. Internal Combustion Engine Fundamentals. McGraw-Hill Education. 960 p.

ISO 3679:2015. Determination of Flash No-Flash and Flash Point - Rapid Equilibrium Closed Cup Method.

ISO 20884:2011. Petroleum Products - Determination of Sulfur Content of Automotive Fuels - Wavelength-Dispersive X-Ray Fluorescence Spectrometry.
İlkılıç, C.; Aydın, H. 2011. Fuel production from waste vehicle tires by catalytic pyrolysis and its application in a diesel engine, Fuel Processing Technology 92(5): 1129-1135.

https://doi.org/10.1016/j.fuproc.2011.01.009

Karmakar, A.; Karmakar, S.; Mukherjee, S. 2010. Properties of various plants and animals feedstocks for biodiesel production, Bioresource Technology 101(19): 7201-7210.

https://doi.org/10.1016/j.biortech.2010.04.079

Kegl, B. 2011. Influence of biodiesel on engine combustion and emission characteristics, Applied Energy 88(5): 1803-1812. https://doi.org/10.1016/j.apenergy.2010.12.007

Kline, S. J.; McClintock, F. A. 1953. Describing uncertainties in single-sample experiments, Mechanical Engineering 75(1): 3-8.

Koc, A. B.; Abdullah, M. 2014. Performance of a 4-cylinder diesel engine running on tire oil-biodiesel-diesel blend, Fuel Processing Technology 18: 264-269. https://doi.org/10.1016/j.fuproc.2013.09.013

Koc, A. B.; Abdullah, M. K.; Schumacher, L. G.; Borgelt, S. 2010. Exhaust emissions of a 4-cylinder diesel engine fueled with biodiesel, tire oil and diesel fuel blends, in ASABE 2010: Annual International Meeting, 20-23 June 2010, Pittsburgh, Pennsylvania, US. https://doi.org/10.13031/2013.29865

Luo, G.; Suto, T.; Yasu, S.; Kato, K. 2000. Catalytic degradation of high density polyethylene and polypropylene into liquid fuel in a powder-particle fluidized bed, Polymer Degradation and Stability 70(1): 97-102.

https://doi.org/10.1016/S0141-3910(00)00095-1

Mikulski, M.; Duda, K.; Wierzbicki, S. 2016. Performance and emissions of a CRDI diesel engine fuelled with swine lard methyl esters-diesel mixture, Fuel 164: 206-219. https://doi.org/10.1016/j.fuel.2015.09.083

Mikulski, M.; Wierzbicki, S. 2012. The concept and construction of the engine test bed for experiments with a multi-fuel $\mathrm{CI}$ engine fed with CNG and liquid fuel as an ignition dose, Journal of KONES Powertrain and Transport 19(3): 289-296. https://doi.org/10.5604/12314005.1138136

Mikulski, M.; Wierzbicki, S. 2016a. Numerical investigation of the impact of gas composition on the combustion process in a dual-fuel compression-ignition engine, Journal of Natural Gas Science and Engineering 31: 525-537. https://doi.org/10.1016/j.jngse.2016.03.074

Mikulski, M.; Wierzbicki, S. 2016b. Validation of a zero-dimensional and 2-phase combustion model for dual-fuel compression ignition engine simulation, Thermal Science 21(1): 387-399. https://doi.org/10.2298/TSCI160127076M

Mulimani, H.; Navindgi, M.C. 2017. An experimental investigation of DI diesel engine fuelled with emulsions of Mahua bio-oil, International Journal of Science and Research 6(1): 1781-1785.

Murugan, S.; Ramaswamy, M. C.; Nagarajan, G. 2008a. A comparative study on the performance, emission and combustion studies of a DI diesel engine using distilled tyre pyrolysis oildiesel blends, Fuel 87(10-11): 2111-2121. https://doi.org/10.1016/j.fuel.2008.01.008

Murugan, S.; Ramaswamy, M. C.; Nagarajan, G. 2008b. Influence of distillation on performance, emission, and combustion of a DI diesel engine, using tyre pyrolysis oil diesel blends, Thermal Science 12(1): 157-167. https://doi.org/10.2298/TSCI0801157M 
Panda, A. K.; Singh, R. K.; Mishra, D. K. 2010. Thermolysis of waste plastics to liquid fuel: a suitable method for plastic waste management and manufacture of value added products: a world prospective, Renewable and Sustainable Energy Reviews 14(1): 233-248. https://doi.org/10.1016/j.rser.2009.07.005

Raslavičius, L.; Bazaras, Ž. 2009. The analysis of the motor characteristics of D-RME-E fuel blend during on-field tests, Transport 24(3): 187-191.

https://doi.org/10.3846/1648-4142.2009.24.187-191

Refaat, A. A. 2010. Different techniques for the production of biodiesel from waste vegetable oil, International Journal of Environmental Science and Technology 7(1): 183-213. https://doi.org/10.1007/BF03326130

Sharma, Y. C.; Singh, B. 2009. Development of biodiesel: current scenario, Renewable and Sustainable Energy Reviews 13(6-7): 1646-1651. https://doi.org/10.1016/j.rser.2008.08.009

Surovka, D.; Pertile, E.; Lorenz, T.; Fećko, P.; Guziurek, M. 2012. Potential energy recovery from waste pyrolytic treatment products, Journal of the Polish Mineral Engineering Society 13: 43-48.

Tańska, M.; Rotkiewicz, D.; Bączek, N. 2012. Adsorpcyjne oczyszczanie tłuszczów posmażalniczych przeznaczonych do produckcji biodiesla, Nauka Przyroda Technologie 6(4): 1-11. (in Polish).

Venderbosch, R. H.; Prins, W. 2010. Fast pyrolysis technology development, Biofuels, Bioproducts and Biorefining 4(2): 178208. https://doi.org/10.1002/bbb.205

Zabaniotou, A. A.; Stavropoulos, G. 2003. Pyrolysis of used automobile tires and residual char utilization, Journal of Analytical and Applied Pyrolysis 70(2): 711-722.

https://doi.org/10.1016/S0165-2370(03)00042-1

Zhang, M.; Wu, H. 2014. Phase behavior and fuel properties of bio-oil/glycerol/methanol blends, Energy \& Fuels 28(7): 4650-4656. https://doi.org/10.1021/ef501176z 